\title{
Getting a Grip on Emotions in Negotiations: the Possibilities of ICT
}

\author{
Willem-Paul Brinkman, Joost Broekens, \\ Catholijn M. Jonker \\ Man-Machine Interaction group \\ Faculty of EEMCS, Delft University of Technology \\ Delft, The Netherlands \\ \{w.p.brinkman, d.j.broekens, c.m.jonker\}@tudelft.nl
}

\author{
John-Jules Ch. Meyer \\ Intelligent Systems group \\ Faculty of Science, Utrecht University \\ Utrecht, The Netherlands \\ jj@cs.uu.nl
}

\begin{abstract}
Negotiation is a daily occurring process at all levels of society. Emotion plays an important role in negotiation between humans. In this paper we discuss to what extent and in which form ICT techniques can be used to get a grip on the emotional processes that play a role during negotiations. We focus on emotion recognition and measurement. Our analysis shows that current emotion recognition \& measurement technology is mainly usable in the preparation for negotiations (including training sessions) and during offline moments of the negotiation (e.g., time-outs). The main arguments for this conclusion are: (1) valid and reliable emotion recognition and measurement techniques are usually invasive, and, (2) it is unclear if participants in a negotiation accept the technology.
\end{abstract}

Keywords-negotiation; negotiation support; emotion

\section{INTRODUCTION}

Negotiation is an important aspect of our daily life. One definition is that it concerns the process of getting an agreement regarding the exchange of goods and services. Although this is definition has a strong flavor of economic rationality it can be used to describe diverse processes such as two parents trying to get an agreement on who will take the children to school, do the groceries and clean the house as well as having the world leaders negotiate $\mathrm{CO} 2$ emissions.

Fisher, Ury and Patton [11], Thompson [34] and others emphasize that negotiation is not just about money, but also about relationships, awareness of all issues (domain model), personal preferences (user and opponent model), knowledge of your alternatives (if no deal is reached), and reflection on your performance. In this paper we focus on the role of emotion in negotiation, see e.g., $[10,17,21,32]$.

Research has shown that emotions and affect influence the negotiation outcome. For example, the best negotiation outcomes are reached when people manage to create and maintain a positive and relaxed atmosphere, see e.g., [3, 21, 34]. Negotiating is an emotional process, certainly for the novice negotiator [37]. The more that depends on the outcome of the negotiation, the more intense the emotions. Negative feelings such as not being in control of the situation, not knowing what to expect, and fearing to underperform inhibit the exchange of information about underlying concerns, whereas in a relaxed atmosphere the additional information broadens the scope of the negotiation
$[30,36]$. In fact, a bad atmosphere and a lack of information are structural barriers to agreement [20].

Furthermore, human negotiators make mental errors some of which are related to emotions; biased perception, irrational expectations, overconfidence, and unchecked emotions [20]. Biased perception is the problem of perceiving the world with a bias to make it fit your view of the situation. According to the literature, these problems are reduced by proper preparation, an effective negotiation style, a good dialogue with the opponent, timely interventions (such as a break), and training, see e.g.,[20, 34].

Interestingly, recent research shows that the display of negative emotions such as anger can in some cases enhance the negotiation outcome for the person showing the negative emotion [31]. However, this beneficial effect is dependent on the strength of the alternatives of the opponent [7, 31].

The role of emotion and affect in negotiation is complex and multifaceted. We study questions such as: how do emotions influence perception and decision making of the one having the emotion, and how do they influence the other party? How do we measure emotion during a negotiation in a for negotiators acceptable way? And, how can we use emotions in a constructive way in the negotiation strategy?

As mentioned above, preparation, negotiation style, good dialogue and training are important to enhance the negotiation outcome. We are developing a negotiation support system called the Pocket Negotiator that supports humans in all these aspects and all phases of negotiation (see Section 2), see [13] for more details on this project. Other negotiation support systems are discussed in e.g., [15, 39].

Here we discuss the possible role of emotion recognition and measurement techniques to support human decision making in the context of negotiation. Sections 2, 3, and 4 form the background of this research. Section 2 discusses the dominant phases in negotiation. The discussions in later sections refer to those phases. Section 3 discusses different theoretical views on emotions. Section 4 provides an outline of the aspects of emotions in negotiations for which technological support is considered. Section 5 discusses emotion recognition and measuring techniques.

\section{PHASES IN NEGOTIATION}

Negotiation starts much earlier than inexperienced negotiators realize. Four major stages can be discerned: 
private preparation, joint exploration, bidding, and closing, see e.g., [13].

Private preparation is about information gathering and reflection before meeting the other party. The negotiator investigates the negotiation domain, his profile and that of the opponent.

Joint exploration: the negotiating parties get to know each other, but don't place bids on the table. The aim of is to check the information gathered so far, to create a good atmosphere, to investigate options, and to agree upon a protocol for the bidding.

Bidding: bids are exchanged. For each incoming bid the negotiator has to decide, whether to accept, to make a counteroffer, or to stop (a better alternative exists elsewhere).

Closing: the outcome of the bidding stage is formalized and confirmed by both parties. If necessary, the negotiation returns to one of the previous stages.

\section{VIEWS ON EMOTION}

As argued in the introduction, emotions have an important impact on the negotiation outcome and process. Emotion researchers within the affective sciences appear to be converging on a high-level definition of emotion, as the "evaluative judgments of the environment, the self and other agents, in light of the agent's personal relevance", and associated coordinated and adaptive behavioral responses. For a survey on emotion literature, see [18]. However, emotion (and therefore its representation in a negotiation support system) can be approached from different perspectives. Below, we briefly list the three main perspectives used in the affective sciences: emotion categories, emotional dimensions, and emotion components.

\section{A. Emotion Categories}

The literature on categories of emotion is extensive. For this paper, we limit ourselves to an example: Ekman and Friesen proposed the following six universal facial expressions: anger, fear, disgust, surprise, happiness, and sadness [8]. The essence is that each emotion has a unique "multi modal program" associated with it (e.g., fear, arousal, flight, sweating are all part of the fear "program"). For an overview of literature on emotional categories see [5].

\section{B. Dimensions of Emotions}

Research on emotion dimensions suggests that emotions arise from cognitive interpretations of core physiological activity [29]. The essence of this perspective is that a limited set of dimensions can describe a large set of emotions by emphasizing commonalities (core physiological activity) between emotions, and deemphasize the uniqueness of individual emotions. An important representative of this perspective is the pleasure, arousal, and dominance (PAD) model [22]. In this model the dimension pleasure refers to pleasantness of the emotions, for example by qualifying the emotion as positive or negative. The arousal dimension refers the extent of bodily activation. The dominance dimension refers to whether the subject is in control, or the environment. Most emotion psychologists agree that at least pleasure (valence) and arousal are core components.

\section{Componential Theories of Emotions}

The third perspective on emotion is the componential view, of which cognitive appraisal theory is a prototypical member. For an overview of appraisal theories, see [9]. Emotions are defined as "valenced reactions to events, agents, or objects, with their particular nature being determined by the way in which the eliciting situation is construed" ([24], p. 13). The essence is that different cognitive processes (components) result in an interpretation of a situation and that this interpretation is a major explaining factor in emotion. It has become a standard model for synthesizing emotions in computers [25] and proved useful for computational reasoning about emotions [33].

\section{ICT SUPPORT IN EMOTIONAL NEGOTIATIONS?}

Negotiators should be aware of the role of emotion, mood, and conflict in negotiation $[11,17,32,34]$. In our aim to providing negotiation support, how do we best support the negotiator in emotional negotiations? Can we help the negotiator (our user) to become aware of the role of emotion and conflict handling styles [16] in negotiations? How can we determine which specific emotions play a role for the user and the other party (also called opponent)? Can we determine conflict handling styles of the user? Can we help the user form an estimate of the opponent's conflict handling styles, his preferences, and his emotional state? Can we help the user to link emotions to events? Can we provide advice regarding emotional situations that are effective given the conflict-handling styles of the user and the opponent?

The literature does not agree on what the "best" way is to negotiate, see [19] for an overview. Still we want to effectively present to the user models of conflict handling, interaction in negotiation, and emotional influences on these. The system needs to incorporate general knowledge about emotions, coping styles and mental models. Emotions and moods, for example, are triggered by a conglomerate of factors such as situation, context, interaction with other people, and physical state, see, e.g., [12, 36]. Successful behavioral responses grow into coping styles [30] of that individual. The way people interact with each other and cope with emotions in a negotiation context depends on their mental model of negotiation, and their conflict-handling style. Five distinct mental models of negotiation have been found [38] that directly affect negotiation performance. As it is also known that affect and emotion influence information processing in humans, having a system that discloses to the user links between mental models and affect, would already support the user to better cope with the situation [14].

The knowledge described above is to form the basis of a tool that provides coping advice that fits the profile of the user and is relevant for the situation the user is in. The next section discusses some techniques that can be of use.

\section{EXISTING TOOLS}

The first bottleneck is emotion recognition, to e.g., alert the negotiator to high levels of arousal in the negotiation. With emotion recognition tools the negotiator can actively analyze the emotional status of either party. An adequate 
view of the emotional state of the negotiators is a prerequisite for influencing the atmosphere. The next step is to assist the user in an emotional negotiation. For that we need tools for recognizing the conflict handling styles and mental models of negotiation of the parties involved. This section provides some information on both topics.

\section{A. Emotion Recognition and Measures}

Poels \& Dewitte [26] provide an overview and comparison of emotion measurement techniques of the last 20 years. Emotion measurement techniques are categorized in three groups, namely self-report measures, autonomic (physiological) measures, and observation-based measures.

\section{1) Self-report techniques}

Self-report techniques measure the user's subjective feeling, which is the consciously felt experience of an emotion as expressed by the individual. Self-report techniques are classified in three groups: verbal self-report, visual self-report, and moment-to-moment ratings. In a verbal self-report the respondent expresses emotions verbally by means of answering open questions or rating items, or in an interview or a diary. Like the verbal ones, visual selfreport techniques measure subjective feelings. But now graphics are used instead of words. Two frequently used ones are the Self-Assessment Manikin [2] and the PrEmo [6]. The Self-Assessment Manikin visually represents the three dimensions of the PAD model (see Section 3) and was designed as an alternative to the sometimes cumbersome verbal self-report measures. Visual self-report is quick and user-friendly. Morris found it suitable for cross-cultural research and applicable for different age groups [23].

In moment-to-moment ratings, respondents rate the strength of the perceived magnitude of an emotional dimension or a specific emotion in relation to a (neutral) reference point. A computerized tool is the "feelings monitor" [1], in which a cursor is moved from left to right indicating positive or negative feelings (valence). Momentto-moment ratings are cheap, user friendly and provide immediate and continuous measurement of emotions.

Obviously self-reports suffer from subjective bias as users report their own perception of their emotional state. Furthermore, subjects might be unwilling to report their emotions (social desirability bias) [26].

The appropriateness of such techniques might be limited to training sessions and moments during the negotiation phases in which the negotiator is away from the other party and has the time to provide the self-report and reflect upon the situation. From a focus group study we found that having a negotiation-support-application (with self-report tool in it) on a PDA during the negotiation can be socially undesirable. More research is needed on these issues.

Subjective bias and social desirability bias can be overcome by measuring reactions such as facial expressions and physiological reactions that are beyond respondents' control, as discussed in the next two sub sections.

\section{2) Autonomic Measures}

Autonomic measuring techniques require attaching measuring equipment to the subjects. Well-known techniques are electrocardiogram (ECG), electro dermal response (EDR), galvanic skin response (GSR), electroencephalogram (EEG), and electromyography (EMG). Prendinger et al. apply such techniques to support users in decision making [27]. As these techniques involve "wiring", for negotiation these seem practically and socially acceptable only during training situations. A related problem is that autonomic measurement aimed at emotion recognition produces difficult-to-interpret data in uncontrolled settings.

\section{3) Observation-based measures}

Observation-based measurement techniques focus on body posture and gestures, facial expressions, and voice characteristics. Interpreting emotions of others is difficult since others may hide or mask their emotions for social or strategic purposes (e.g. poker face). Technology to determine emotional status based on visual and audio signals is under development, see e.g., [4, 28, 35]. Even such non-intrusive techniques are probably not socially acceptable in real faceto-face negotiations.

To conclude, self-reporting techniques currently seem to be most suitable during those negotiation phases in which the negotiator is in contact with the other party. All other techniques seem only appropriate for negotiation training sessions. However, can self-reporting techniques be used reliable by the user to form an idea of the emotional status of the opponent in the heat of a real negotiation?

\section{B. Mental Models \& Conflict Handling Styles}

Having insight in their conflict-handling style [16] and that of their opponent can help negotiators to predict possible sources of conflict, and ways to avoid or alleviate conflict. We need tools to elicit information from the user on the conflict-handling styles of both parties, and on their mental model of negotiation. The existing tools for determining conflict handling styles, see e.g., [16], can be incorporated in our system to determine the conflict handling style of the user, but leaves open the problem of identifying the style of the opponent. Similarly, the research of Van Boven and Thompson [38] can be used to devise a tool for determining a user's mental model of negotiation, but that does not help us with the determination of such mental model of the opponent. An important direction for future research is how to integrate (e.g., how to measure, model, reason about) emotions and affect in mental models and conflict handling styles in such a way that negotiation support systems can help users to strategically use, and cope with their and others' emotions.

\section{CONCLUSION}

We have shown that emotion is an important concept to consider in a negotiation support system that can be used during real-time negotiations. Being able to model the role of emotions in negotiation can help users to better understand how emotions can be useful and detrimental to the negotiation outcome and long-term relation with the opponent. A current challenge is that many of the existing techniques for measuring emotions in an objective and automatic way are difficult to integrate in systems aimed at supporting negotiators in real time, emotional negotiations. However, these techniques can be applied in training 
situations. For real situations, emotion measurement might have to rely on self-report techniques, where the user has to report his/her own emotions as well as those of the opponent.

\section{ACKNOWLEDGMENT}

This research is supported by the Dutch Technology Foundation STW, applied science division of NWO and the Technology Program of the Ministry of Economic Affairs, Pocket Negotiator project, VIVI-project grant nr. 08075.

\section{REFERENCES}

[1] H. Baumgartner, M. Sujan, and D. Padgett, "Patterns of Affective Reactions to Advertisements: The Integration of Moment-to-Moment Responses into Overall Judgments," Journal of Marketing Research, vol. 34, no. 2, 1997, pp. 219-232.

[2] M.M. Bradley, and P.J. Lang, "Measuring emotion: the SelfAssessment Manikin and the Semantic Differential," Journal of Behav Ther Exp Psychiatry, vol. 25, 1994, pp. 49-59.

[3] P.J.D. Carnevale, and A.M. Isen, "The influence of positive affect and visual access on the discovery of integrative solutions in bilateral negotiation," Organizational Behavior and Human Decision Processes, vol. 37 , no. 1, 1986, pp. 1-13.

[4] L.S. Chen, "Joint processing of audio-visual information for the recognition of emotional expressions in human-computer interaction," University of Illinois at Urbana-Champaign, Dept. of Elect. Eng, 2001.

[5] R. Cowie, and R.R. Cornelius, "Describing the emotional states that are expressed in speech," Speech Communication, vol. 40, no. 1-2, 2003, pp. 5-32.

[6] P. Desmet, "Measuring emotion: development and application of an instrument to measure emotional responses to products," Funology: from usability to enjoyment, Kluwer Academic Publishers, 2004, pp. 111-123.

[7] E.v. Dijk, G.A.v. Kleef, W. Steinel, and I.v. Beest, "A Social Functional Approach to Emotions in Bargaining: When Communicating Anger Pays and When it Backfires," Journal of Personality and Social Psychology, vol. 94, 2008, pp. 600-614.

[8] P. Ekman, and W. Friesen, Unmasking the face: A guide to recognizing emotions from facial expressions., Cambridge, MA: Malor Books, 2003

[9] P.C. Ellsworth, and K.R. Scherer, "Appraisal processes in emotion," Handbook of the affective sciences, R.J. Davidson, Goldsmith, H.H. and Scherer, K.R. ed., Oxford University Press, 2003, pp. 572-595.

[10] R. Fisher, and D. Shapiro, Beyond reason: using emotions as you negotiate, Random House Business Books, 2005.

[11] R. Fisher, W. Ury, and B. Patton, Getting to yes: negotiating agreement without giving in, Houghton Mifflin Harcourt, 1991.

[12] N.H. Frijda, "The Psychologists' Point of View," Handbook of emotions, M. Lewis, J.M. Haviland-Jones, and L.F. Barrett eds., Guilford Press, 2008, pp. 68-87.

[13] K.V. Hindriks, and C.M. Jonker, "Creating Human-Machine Synergy in Negotiation Support Systems: Towards the Pocket Negotiator," Proc. of the 1st Int. Working Conference on Human Factors and Computational Models in Negotiation, HuCom 2008, W.-P. Brinkman ed., 2008, pp. 47-54.

[14] D. Kahneman, "A perspective on judgment and choice: Mapping bounded rationality.," American Psychologist, vol. 58, no. 9, 2003, pp. 697-720.

[15] G. Kersten, and D. Cray, "Perspectives on representation and analysis of negotiation: Towards cognitive support systems," Group Decision and Negotiation, vol. 5, no. 4, 1996, pp. 433-467.

[16] R.H. Kilmann, and K.W. Thomas, "Developing a Forced-Choice Measure of Conflict-Handling Behavior: The "Mode" Instrument," Educational and Psychological Measurement, vol. 37, no. 2, 1977, pp. 309-325.
[17] G.A.v. Kleef, De Dreu, C.K.W., and Manstead, A.S.R., , "The Interpersonal Effects of Emotions in Negotiations: A Motivated Information Processing Approach," Journal of Personality \& Social Psychology, vol. 87, no. 4, 2004, pp. 510-528.

[18] P.R. Kleinginna, and A.M. Kleinginna, "A categorized list of emotion definitions, with suggestions for a consensual definition," Motivation and Emotion, vol. 5, no. 4, 1981, pp. 345-379.

[19] R.J. Lewicki, S.E. Weiss, and D. Lewin, "Models of Conflict, Negotiation and Third Party Intervention: A Review and Synthesis," Journal of Organizational Behavior, vol. 13, no. 3, 1992, pp. 209-252.

[20] R. Luecke, Harvard business essentials: negotiation, Harvard Business School Press, 2003.

[21] W. Mastenbroek, "Negotiating as Emotion Management," Theory Culture Society, vol. 16, no. 4, 1999, pp. 49-73.

[22] A. Mehrabian, \& Russell, J.A. , "A verbal measure of information rate for studies in environmental psychology," Environment and Behavior, vol. 6,1974 , pp. 233-252.

[23] J.D. Morris, "SAM: the Self-Assessment Manikin. An efficient crosscultural measurement of emotional response," Journal of Advertising Research, vol. Nov, 1995.

[24] A. Ortony, G.L. Clore, and A. Collins, The Cognitive Structure of Emotions, Cambridge University Press, 1988.

[25] R.W. Picard, Affective Computing, MIT Press, 1997.

[26] K. Poels, and S. Dewitte, "How to Capture the Heart? Reviewing 20 Years of Emotion Measurement in Advertising," Journal of Advertising Research, vol. 46, no. 1, 2006, pp. 18-37.

[27] H. Prendinger, and M. Ishizuka, "THE EMPATHIC COMPANION: A CHARACTER-BASED INTERFACE THAT ADDRESSES USERS AFFECTIVE STATES," Applied Artificial Intelligence: An International Journal, vol. 19, no. 3, 2005, pp. 267 - 285.

[28] L.J.M. Rothkrantz, P. Wiggers, J.-W.A. van Wees, and R.J. van Vark, "Voice Stress Analysis," Text, Speech and Dialogue, 2004, pp. 449456.

[29] J. Russell, "Core affect and the psychological construction of emotion," Psychological Review, vol. 110, no. 1, 2003, pp. 145-172.

[30] S. Folkman, and R.S. Lazarus, "Coping and emotion," Psychological and Biological Approaches to Emotion, N.L. Stein, B. Leventhal, and T. Trabasso eds., Lawrence Erlbaum, 1990, pp. 313-332.

[31] M. Sinaceur, and L.Z. Tiedens, "Get mad and get more than even: When and why anger expression is effective in negotiations," Journal of Experimental Social Psychology, vol. 42, no. 3, 2006, pp. 314-322.

[32] W. Steinel, G.A. Van Kleef, and F. Harinck, "Are you talking to me?! Separating the people from the problem when expressing emotions in negotiation," Journal of Experimental Social Psychology, vol. 44, no. 2, 2008, pp. 362-369.

[33] B.R. Steunebrink, M. Dastani, and J.-J.C. Meyer, "A Logic of Emotions for Intelligent Agents," Proceedings of the 22th National Conference on Artifical Intelligence (AAAI '07), AAAI Press, 2007, pp. 142-147.

[34] L.L. Thompson, The Heart and Mind of the Negotiator, Pearson Prentice Hall, 2005.

[35] K. Truong, D. van Leeuwen, and M. Neerincx, "Unobtrusive Multimodal Emotion Detection in Adaptive Interfaces: Speech and Facial Expressions," Foundations of Augmented Cognition, 2007, pp. 354-363.

[36] H. Ursin, and H.R. Eriksen, "The cognitive activation theory of stress," Psychoneuroendocrinology, vol. 29, no. 5, 2004, pp. 567-592.

[37] W. Ury, The Power of a Positive No: How to Say No and Still Get to Yes, Bantam Books / Random House, 2007.

[38] L. Van Boven, and L. Thompson, "A Look into the Mind of the Negotiator: Mental Models in Negotiation," Group Processes Intergroup Relations, vol. 6, no. 4, 2003, pp. 387-404.

[39] J. Zeleznikow, "Risk, negotiation and argumentation--a decision support system based approach," Law Probablity and Risk, vol. 1, no. 1,2002 , pp. $37-48$ 